\title{
Barraquer-Simons syndrome: a unique patient's perspective on diagnosis, disease progression and recontouring treatment
}

\author{
Lene Nyhøj Heidemann, Jørn Bo Thomsen, Jens Ahm Sørensen
}

Department of Plastic and Reconstructive Surgery, Odense University Hospital, Odense, Denmark

\section{Correspondence to} Dr Lene Nyhøj Heidemann, lenenyhoj@gmail.com

Accepted 26 June 2016
CrossMark

To cite: Heidemann $L N$, Thomsen JB, Sørensen JA. BMJ Case Rep Published online: [please include Day Month Year] doi:10.1136/ bcr-2016-216134

\section{SUMMARY}

This case report describes a female patient diagnosed with Barraquer-Simons syndrome, a rare form of acquired partial lipodystrophy characterised by symmetrical loss of adipose tissue from face, neck, upper extremities and the trunk with onset in early childhood. Initial symptoms were seen at the age of 8 years. Our patient did not show signs of renal impairment and this may be associated with the syndrome. Treatment of lipoatrophy in these patients is limited to cosmetic restoration, and autologous fat grafting has shown sustained positive effects with no or very little loss of volume at follow-ups. Furthermore, the treatment has resulted in considerable improvements in her quality of life and daily functioning. She has not experienced any adverse effects. Accurate and early diagnosis is important, and clinicians should consider early intervention for these patients. Autologous fat grafting is recommended as a safe procedure.

\section{BACKGROUND}

Barraquer-Simons syndrome (BSS) is a rare form of acquired partial lipodystrophy characterised by slow, progressive subcutaneous lipoatrophy, with symmetrical loss of adipose tissue from the face, neck, upper extremities, thorax and abdomen, but sparing the lower extremities. Approximately 250 cases have been reported worldwide. ${ }^{1}$ Although the aetiology is mostly unknown, genetic factors and autoimmunity are thought to play a role. Women are more often affected than men (female-male ratio of 4:1) and onset occurs before the age of 15 years in most patients. ${ }^{12}$ One-fourth will develop glomerulonephritis. Most patients display low serum levels of Complement 3 and presence of serum C3-nephritic factor, an autoantibody that induces lysis of adipocytes. ${ }^{3}{ }^{4}$ Subcutaneous tissue biopsy will show decreased adipocyte volume in affected areas. ${ }^{4}$ BSS is generally not associated with metabolic abnormalities, and this is in contrast to most other forms of lipodystrophy. ${ }^{15}$ No treatment exists at present to halt the progression of lipoatrophy and therefore, treatment is limited to cosmetic restoration of affected areas. ${ }^{15}$ We report a rare case of a patient with BSS treated with autologous fat grafting (AFG).

\section{CASE PRESENTATION}

In February 2011, a 34-year-old woman was referred to the department of Plastic and Reconstructive Surgery, Odense University Hospital, to assess her medical condition and determine if treatment with AFG would be possible. The woman was diagnosed with BSS at the age of 19 years. However, onset of lipoatrophy occurred when she
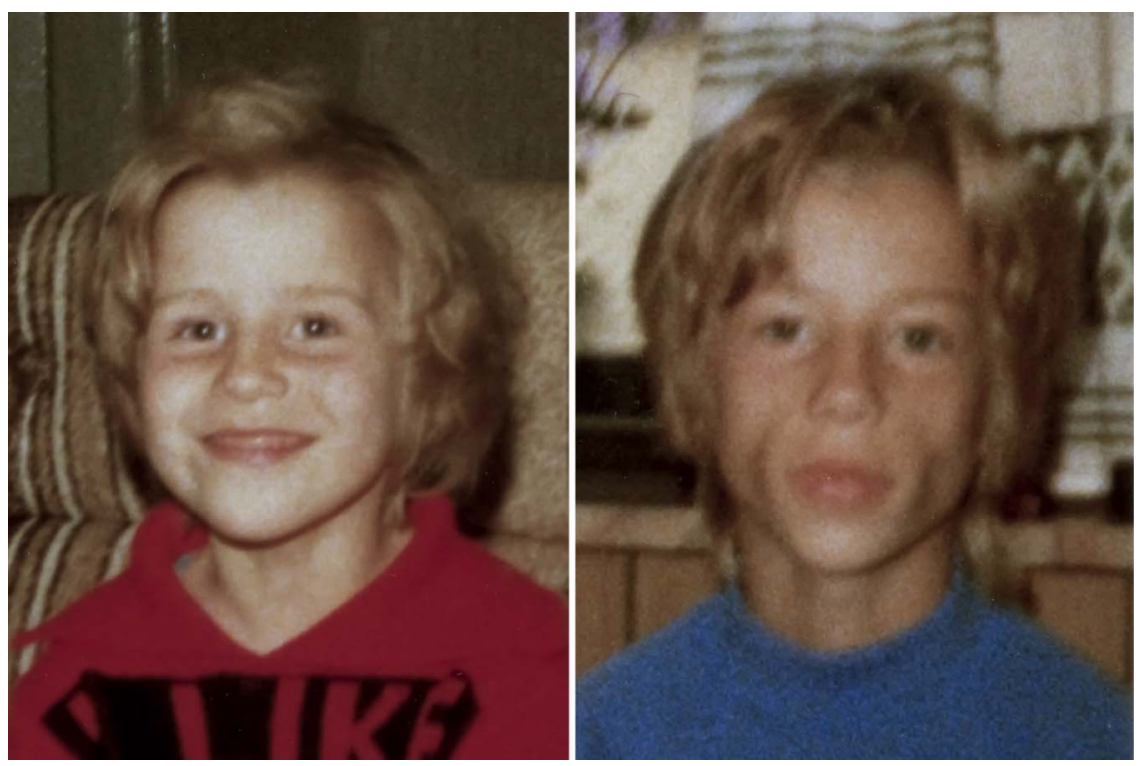

Figure 1 Pictures of the patient at age 6 and 10 years. Onset of Barraquer-Simons syndrome occurred when the patient was $\sim 8$ years old (private photo). 


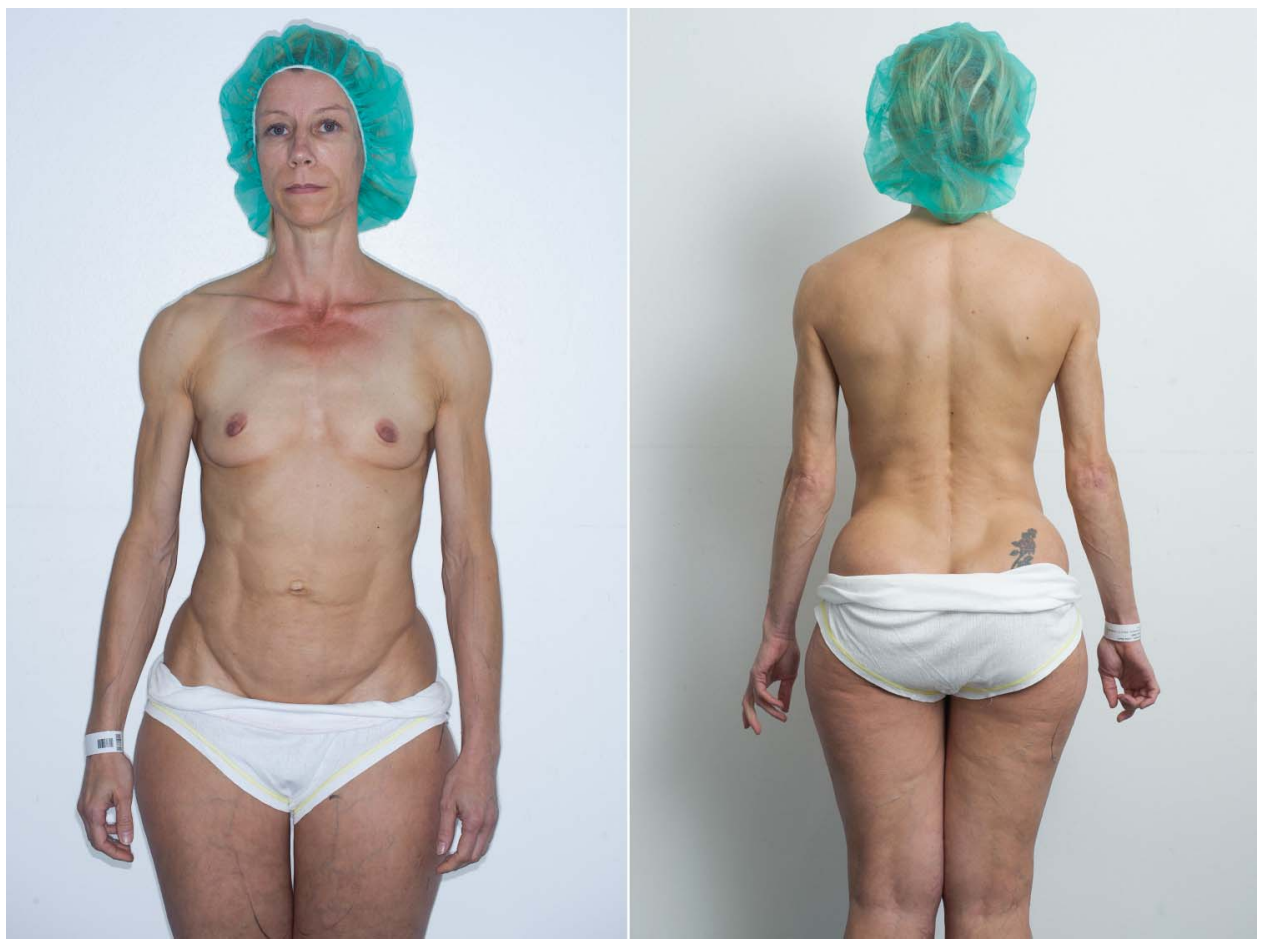

Figure 2 Adipose tissue distribution in patients with Barraquer-Simons syndrome. Lipoatrophy extending to the lower part of the abdomen and excessive adipose tissue on the lower extremities.

was $\sim 8$ years old (figure 1 ). For years she was mistakenly suspected of suffering from anorexia nervosa and was admitted to the hospital several times. The onset of the symmetrical loss of subcutaneous adipose tissue occurred in the face, and progressed to the upper extremities and trunk extending to the lower part of the abdomen. The patient has excessive adipose tissue on the hips and lower extremities (figure 2). She suffers from mild hypertension, but testing revealed no signs of diabetes, autoimmune diseases, HIV or incipient glomerulonephritis. Furthermore, blood tests have not shown presence of C3-nephritic factor. Emotionally, the patient experiences low self-esteem, exhibits introvert behaviour and suffers impaired overall quality of life (QoL) for longer periods of time. Finding employment has been troublesome due to her physical appearance.

\section{TREATMENT}

Autologous fat grafting harvested from the lower extremities has been performed three times ad modum Coleman ${ }^{6}$ (table 1) (figure 3). Prior to harvesting, the area was injected with Ringer's

Table 1 Treatment regimen

\begin{tabular}{llllll}
\hline Treatment & Face & & & Breast & \\
\cline { 2 - 3 } \cline { 5 - 6 } & $\begin{array}{l}\text { Right side } \\
(\mathbf{m L})\end{array}$ & $\begin{array}{l}\text { Left side } \\
(\mathbf{m L})\end{array}$ & & $\begin{array}{l}\text { Right side } \\
(\mathbf{m L})\end{array}$ & $\begin{array}{l}\text { Left side } \\
(\mathbf{m L})\end{array}$ \\
\hline $\begin{array}{l}\text { 1st treatment -April } \\
2014\end{array}$ & 15 & 16 & NT & NT \\
$\begin{array}{l}\text { 2nd treatment }- \\
\text { September 2014 }\end{array}$ & 7 & 9 & 110 & 100 \\
$\begin{array}{l}\text { 3rd treatment - } \\
\text { January 2016 }\end{array}$ & 8 & 7 & 15 & 160 \\
\hline
\end{tabular}

$\mathrm{mL}$, millilitre transplanted adipose tissue; NT, no treatment.
Lactate mixed with epinephrine $(1 \mathrm{ml} / \mathrm{L})$. The graft was centrifuged at $3000 \mathrm{rpm}$ for $3 \mathrm{~min}$, and viable fat was separated and injected using $1 \mathrm{cc}$ syringes. Prophylactic antibiotic treatment was administered before each treatment (intravenous cefuroxime $1.5 \mathrm{~g})$.

\section{OUTCOME AND FOLLOW-UP}

Follow-up visits were conducted 3 months after each treatment. Very little loss of volume has been seen in the face or breasts at the follow-ups, and the patient expressed great satisfaction with treatment (figure 4). So far the patient has not experienced adverse effects (infection, pain or asymmetry).

\section{DISCUSSION}

Acquired lipoatrophy most often occurs in the course of connective tissue diseases, such as systemic lupus erytemathosus and localised scleroderma (Parry-Romberg syndrome), and as an

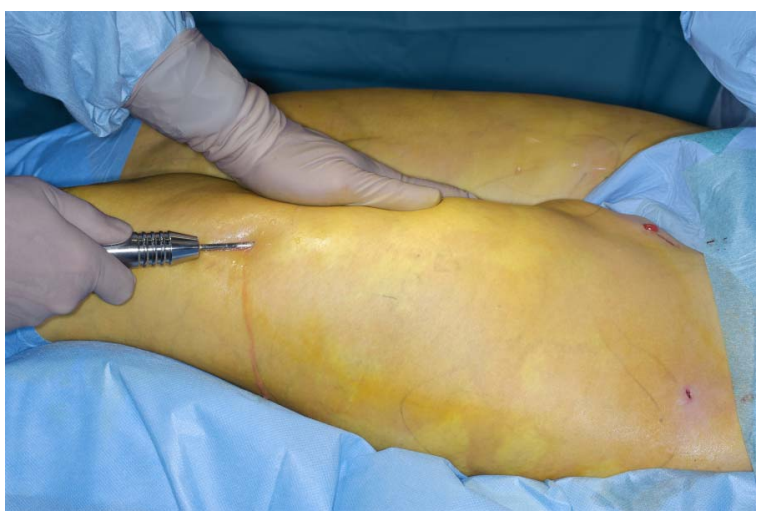

Figure 3 Harvesting of tissue graft from areas with excessive adipose tissue. 

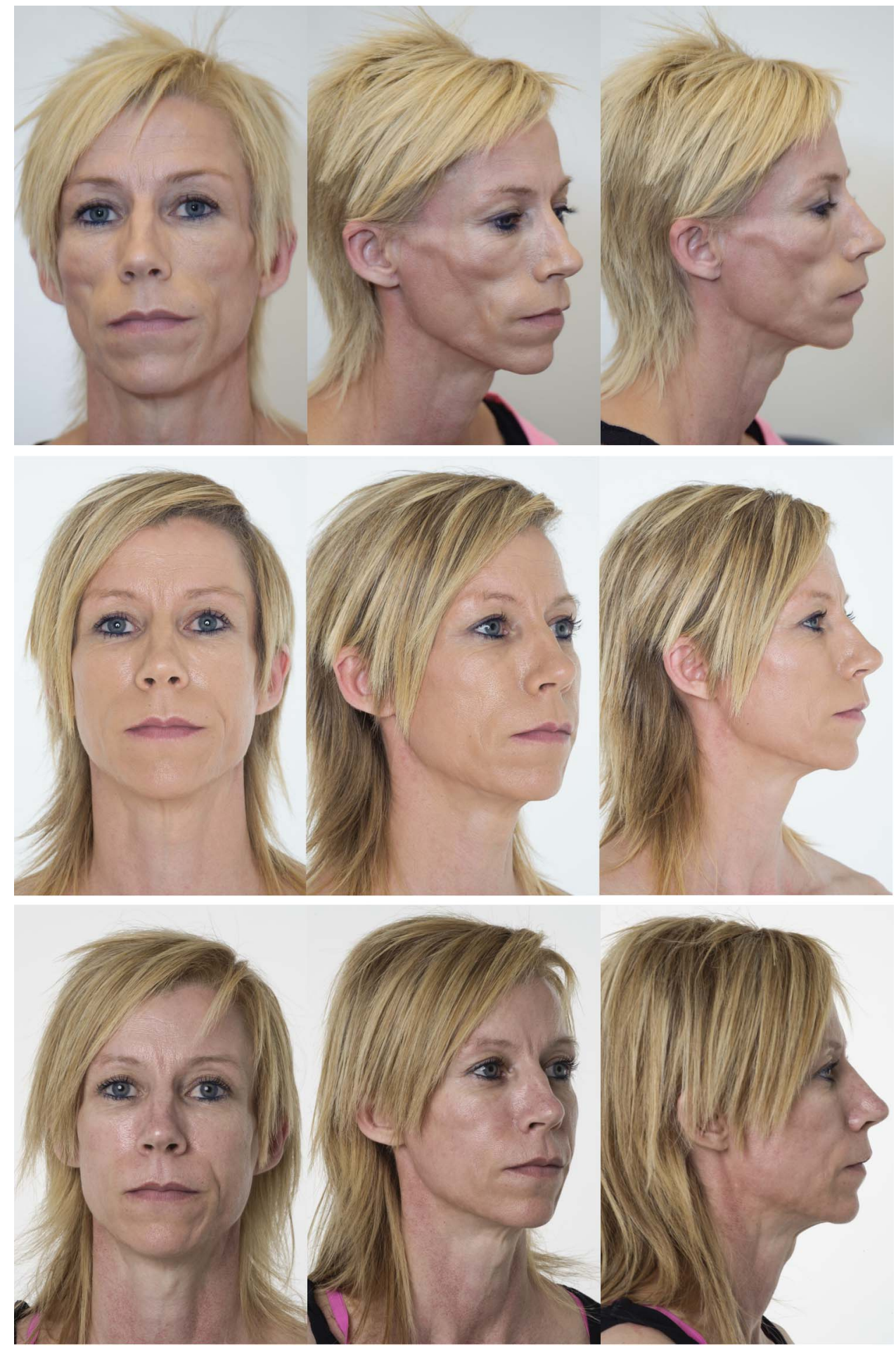

Figure 4 Pictures taken before treatment (March 2013-top row), 3 months after the second treatment (December 2014-middle row) and 3 months after the third treatment (April 2016-bottom row).

adverse effect of antiretroviral treatment in HIV patients. ${ }^{7}$ Lipoatrophy as seen in BSS is rare compared to these conditions and the syndrome, let alone treatment, is only sparsely described in international literature.

Accurate and early diagnosis in patients with BSS seems crucial for several reasons. Although our patient did not present with signs of renal disease, one-fourth of patients with BSS may develop glomerulonephritis. The clinical course of glomerulonephritis in patients with BSS with renal impairment is variable, but $\sim 40-50 \%$ will slowly develop end-stage renal dysfunction.
These patients most often present with asymptomatic proteinuria and microscopic haematuria. ${ }^{4}$ Therefore, a follow-up regimen has been planned for our patient with periodic tests of the renal function and insulin resistance, including urinary protein testing, blood pressure measurements and blood tests. BSS is a rare disease mainly diagnosed by the distinct clinical features. However, given the broad spectrum of differential diagnoses there is a risk of overlooking this disease. Despite normal appetite and energy intake, our patient was suspected of having anorexia nervosa. Several other female patients with BSS 
have also mistakenly been considered to have anorexia nervosa. ${ }^{4}$ Other types of lipodystrophies should also be differentiated from BSS. These patients will often present with other clinical features and unlike BSS, these types are often associated with autoimmune, metabolic and hormonal abnormalities. ${ }^{1}$ Therefore, initial examination of patients with lipodystrophy should include assessment of physical appearance, including signs of insulin resistance (eg, hirsutism and acanthosis nigricans), history of menstrual disorders as well as of laboratory tests. Finally, patients with BSS are often emotionally affected, especially by their facial appearance. Our patient experienced severe emotional distress and impaired QoL. This is in concordance with other studies regarding patients with lipoatrophy. Studies on HIV patients with lipodystrophy found that lipoatrophy is likely to cause anxiety and lowered QoL. ${ }^{8-10}$ Furthermore, the severity of lipoatrophy is correlated with severity of QoL impairment. ${ }^{8}$ Similar findings have been reported in a study on patients with Parry-Romberg syndrome. ${ }^{11}$ Our patient experienced feelings of unattractiveness and less desirability, and we believe early intervention could benefit these patients as they are affected during adolescence.

Compared to reconstructive techniques using artificial fillers, autologous adipose tissue seems ideal as it is readily available,

\section{Patient's perspective}

- The section is based on three telephone interviews, and gives a perspective on the patient's thoughts and concerns on the syndrome itself and the process from deciding on treatment to experiencing the effect of treatment.

- I first noticed changes in bodily appearance when I was around 8-9 years old, but was not diagnosed with Barraquer-Simons syndrome until the age of 19 years. In the intervening years, I was admitted to hospitals several times with decreased general condition and fatigue. Furthermore, I was admitted to a psychiatric hospital for 1 month at the age of 18 years as I was suspected of having an eating disorder. Anorexia nervosa had been suspected for a longer period of time prior to admission. During my upbringing, I have experienced constant attention concerning my diet from my surroundings. My mother tried to fatten me in different ways without success. I experienced extensive bullying during childhood because of my appearance, and I actually tried to fill my cheeks with cotton wool for a while in an attempt to look normal. Feelings of low self-esteem continued during adolescence, especially prior to diagnosis. I felt unattractive and not as pretty as the other girls. I often felt that people frowned on me, especially when I went out with my older sister.

- I was never diagnosed with depression, but have felt depressed for longer periods of time because of my looks. Finally, it was often difficult for me to get jobs as people perceived me as weak and fragile.

- I had come to terms with my looks when I was offered autologous fat grafting treatment. I had a husband and three children, and was reluctant at first as I was concerned about asymmetry or even deformity. However, the treatment has been a success and has definitely improved my self-esteem and overall quality of life. Fortunately, I have not experienced any adverse effects and the results have exceeded my expectations. I have recently finished a nutritionist degree and have a stable job.

\section{Learning points}

- Early and accurate diagnosis is important in patients with Barraquer- Simons syndrome and initial examination must include both assessment of physical appearance as well as laboratory tests.

- One-fourth of patients will develop glomerulonephritis that may result in end-stage renal failure.

- Treatment of lipoatrophy in Barraquer-Simons syndrome is limited to cosmetic restoration.

- Autologous fat grafting has proven to be a successful and safe treatment option for restoring facial contours and breast volume in a patient with Barraquer-Simons syndrome.

- Early intervention should be considered as these patients are affected during adolescence.

inexpensive, enables a natural feeling and does not cause adverse immunological reactions. ${ }^{12}$ However, the durability of autologous tissue grafts is uncertain in patients with BSS due to the progressive nature of the lipoatrophy, and multiple treatments may be necessary to obtain sustained acceptable results. Our patient has so far received three treatments over a time period of nearly 3 years. She has experienced long-lasting positive effects from the treatment. Similar findings have been presented in a previously published case report of AFG treatment for BSS with stable results at 2-year follow-up, but near disappearance of volume after 4 years. ${ }^{13}$ Furthermore, a review on AFG for HIV patients with progressive facial lipoatrophy found sustained improvements for at least 1 year and up to 4 years. ${ }^{14}$

AFG is considered a safe procedure, and adverse events most often include transient pain and discomfort. ${ }^{14}$ Our patient has not experienced any adverse treatment effects. However, she has experienced important changes in her overall quality of life as a result of treatment. Her social life has improved, and she is more outgoing. The subjective changes experienced by the patient are in concordance with reports on acquired facial lipoatrophy in HIV patients. A recent review reported that nearly $80 \%$ of the HIV patients treated with AFG demonstrated significant improvements on the Global Aesthetic Improvement Scale following treatment with AFG. ${ }^{15}$

Contributors LNH drafted the manuscript and interviewed the patient. All authors contributed substantially to the conception and design of the manuscript. All the other authors revised the manuscript critically for important intellectual content. All the authors have approved the submitted final version.

Competing interests None declared.

Patient consent Obtained.

Provenance and peer review Not commissioned; externally peer reviewed.

\section{REFERENCES}

1 Garg A. Lipodystrophies: genetic and acquired body fat disorders. J Clin Endocrinol Metab 2011;96:3313-25.

2 Garg A. Acquired and inherited lipodystrophies. N Engl J Med 2004;350:1220-34.

3 Simsek-Kiper PO, Roach E, Utine GE, et al. Barraquer-Simons syndrome: a rare clinical entity. Am J Med Genet A 2014;164A:1756-60.

4 Misra A, Peethambaram A, Garg A. Clinical features and metabolic and autoimmune derangements in acquired partial lipodystrophy: report of 35 cases and review of the literature. Medicine (Baltimore) 2004;83:18-34.

5 Capeau J, Magré J, Caron-Debarle M, et al. Human lipodystrophies: genetic and acquired diseases of adipose tissue. Endocr Dev 2010;19:1-20.

6 Coleman SR. Facial recontouring with lipostructure. Clin Plast Surg 1997;24:347-67. 
7 Szczerkowska-Dobosz A, Olszewska B, Lemańska M, et al. Acquired facial lipoatrophy: pathogenesis and therapeutic options. Postepy Dermatol Alergol 2015;32:127-33.

8 Guaraldi G, Murri R, Orlando G, et al. Severity of lipodystrophy is associated with decreased health-related quality of life. AIDS Patient Care STDS 2008;22:577-85.

9 Leclercq P, Goujard C, Duracinsky M, et al. High prevalence and impact on the quality of life of facial lipoatrophy and other abnormalities in fat tissue distribution in HIV-infected patients treated with antiretroviral therapy. AIDS Res Hum Retroviruses 2013;29:761-8.

10 Verolet CM, Delhumeau-Cartier C, Sartori M, et al. Lipodystrophy among HIV-infected patients: a cross-sectional study on impact on quality of life and mental health disorders. AIDS Res Ther 2015;12:21.
11 Raposo-Amaral CE, Denadai R, Camargo DN, et al. Parry-Romberg syndrome: severity of the deformity does not correlate with quality of life. Aesthetic Plast Surg 2013;37:792-801.

12 Winters R, Moulthrop T. Is autologous fat grafting superior to other fillers for facial rejuvenation? Laryngoscope 2013;123:1068-9.

13 Ducours JL, Poizac $P$, Ardanza B, et al. Barraquer-Simons syndrome and facial lipo-filling. Apropos of a case. Rev Stomatol Chir Maxillofac 1991;92:105-11.

14 Jagdeo J, Ho D, Lo A, et al. A systematic review of filler agents for aesthetic treatment of HIV facial lipoatrophy (FLA). J Am Acad Dermatol 2015;73:1040-54.

15 Rauso R, Curinga G, Santillo V, et al. Comparison between lipofilling and a nonabsorbable filler for facial wasting rehabilitation in HIV-positive patients. J Craniofac Surg 2011;22:1684-8.

Copyright 2016 BMJ Publishing Group. All rights reserved. For permission to reuse any of this content visit http://group.bmj.com/group/rights-licensing/permissions.

BMJ Case Report Fellows may re-use this article for personal use and teaching without any further permission.

Become a Fellow of BMJ Case Reports today and you can:

- Submit as many cases as you like

- Enjoy fast sympathetic peer review and rapid publication of accepted articles

- Access all the published articles

- Re-use any of the published material for personal use and teaching without further permission

For information on Institutional Fellowships contact consortiasales@bmjgroup.com

Visit casereports.bmj.com for more articles like this and to become a Fellow 